\title{
MENGUPAYAKAN PENJAGAAN TIDAK FORMAL MERENTAS GENDER: EMPOWERING INFORMAL CARE GIVERS ACROSS GENDER
}

\author{
Mohd. Suhaimi Mohamad \\ Pensyarah Kanan, Program Kerja Sosial, Pusat Penyelidikan Psikologi dan Kesejabteraan Manusia, \\ Fakulti Sains Sosial dan Kemanusiaan, Universiti Kebangsaan Malaysia. \\ E-mail:msubaimi@ukm.edu.my \\ Fatimah Abdullah \\ Mantan Profesor Madya, Program Kerja Sosial, Pusat Pengajian Psikologi dan Pembangunan Manusia, \\ Fakulti Sains Sosial dan Kemanusiaan, Universiti Kebangsaan Malaysia. \\ E-mail:fatimahabdullah.dr@gmail.com \\ Farid Mat Zain \\ Pensyarah Kanan, Jabatan Pengajian Arab dan Tamadun Islam, Fakulti Pengajian Islam, \\ Universiti Kebangsaan Malaysia. \\ E-mail:farid@ukm.edu.my
}

Diterima: 12 Agustus $2018 \quad$ Direvisi: 15 September 2018

Diterbitkan: 31 Desember 2018

\begin{abstract}
In many traditional societies, women play an important role as informal caregiver. They take care of small children, family members who are disabled, old and frail. They perform their role within the private family sphere without much complaints. However when many women enter labour force outside their family many of them can no longer become family care giver. The seperation between nuclear familes and extended families due to rural urban migration makes older women like mothers and mothers in-law can no longer available to provide help. As an alternative, many urban families opt for domestic help to look after their young children, disabled family members and the elderly. Domestic helpers continue their domestic chores as instructed by the lady of the house an at the same time perform caregiving role. The important issue related to having domestic maid to perform care giving role especially in Muslim family is regarding physical contact. Most of the activities in caregiving roles involves physical contact especially during cleaning patients body, changing their clothes, prepare their bed, feeding them, bolding their hands and body for therapy. However Islamic paractice do not allow physical contact like touching between two people who are not close family relations or mabram. Since most of domestic maid who also perform the role as caregiver are women, therefore the issue of empowering men to become caregiver is very important because the needs of male caregivers to care for male patients is increasing. Based onwhat is stated in the Quran and hadith and related documents, this paper will outline the need for informal care in families and communities that need to be addressed, particularly those who are Syariahcompliant. Cases from research in the relevant field will be presented to highlight the issues why men should be encourage to consider role as informal caregivers.
\end{abstract}

Keywords: gender, informal care giver, care giving, family.

\begin{abstract}
Abstrak
Dalam banyak masyarakat tradisional, perempuan memainkan peran penting sebagai pengasuh informal. Mereka merawat anak-anak kecil, anggota keluarga yang cacat, tua dan lemah. Mereka melakukan peran mereka dalam ruang keluarga pribadi tanpa banyak keluhan. Namun ketika banyak perempuan memasuki angkatan kerja di luar keluarga mereka, banyak dari mereka tidak bisa lagi menjadi pemberi perawatan keluarga. Pemisahan antara keluarga inti nuklir dan keluarga besar karena migrasi perkotaan pedesaan membuat perempuan yang lebih tua seperti ibu dan ibu mertua tidak lagi dapat menyediakan bantuan. Sebagai alternatif, banyak keluarga perkotaan memilih bantuan rumah tangga untuk menjaga anak-anak mereka, anggota keluarga yang cacat dan orang tua. Pembantu rumah tangga melanjutkan pekerjaan
\end{abstract}


rumah tangga mereka seperti yang diperintahkan oleh nyonya rumah dan pada saat yang sama melakukan peran pengasuhan. Masalah penting terkait dengan memiliki pembantu rumah tangga untuk melakukan peran memberi perawatan terutama dalam keluarga Muslim adalah tentang kontak fisik. Sebagian besar kegiatan dalam peran pengasuhan melibatkan kontak fisik terutama selama membersihkan tubuh pasien, mengganti pakaian, menyiapkan tempat tidur, memberi makan, memegang tangan dan tubuh untuk terapi. Namun paraktek Islam tidak mengizinkan kontak fisik seperti menyentuh antara dua orang yang tidak memiliki hubungan keluarga atau mahram. Karena sebagian besar pembantu rumah tangga yang juga berperan sebagai pengasuh adalah perempuan, maka masalah pemberdayaan lakilaki untuk menjadi pengasuh sangat penting karena kebutuhan pengasuh laki-laki untuk merawat pasien laki-laki semakin meningkat. Berdasarkan apa yang dinyatakan dalam AlQuran dan hadits dan dokumen terkait, makalah ini akan menguraikan kebutuhan untuk perawatan informal dalam keluarga dan masyarakat yang perlu ditangani, terutama mereka yang mematuhi Syariah. Kasus-kasus dari penelitian di bidang yang relevan akan disajikan untuk menyoroti masalah mengapa laki-laki harus didorong untuk mempertimbangkan peran sebagai pengasuh informal.

Kata kunci: gender, pemberi perawatan informal, pengasuhan, keluarga.

\section{Pengenalan}

Kemajuan dalam bidang perubatan merupakan antara faktor penting yang telah menyebabkan peningkatan jangka hayat.Ini menjadikan semakin ramai penduduk di kebanyakan negara yang dapat hidup lebih lama berbanding dengan masa dahulu. Sebagai contoh jangka hayat dalam kalangan penduduk di Malaysia pada tahun 2016 ialah 72.6 tahun berbanding dengan 71.9 tahun 2000. Secara terperinci seorang lelaki yang berumur 65 tahun pada 2016 dijangka dapat hidup selama 14.9 tahun lagi sementara perempuan pula dapat hidup selama 16.9 tahun lebgi. Ini bermakna lelaki yang berumur 65 tahun pada 2016 akan hidup sehingga 79.9 tahun sementara wanita pula boleh hidup sehingga 81.9 tahun (Jabatan Perangkaan Malaysia 2016). Ini bermakna bilangan warga tua yang memerlukan penjagaan akan meningkat pada tahun-tahun akan datang. Selain peningkatan bilangan warga tua, bilangan penduduk yang memerlukan penjagaan berpanjangan juga meningkat disebabkan pelbagai penyakit kronik, sakit mental dan ketidakupayaan. Memandangkan kebanyakan pesakit atau mereka yang kurang upaya akan tinggal bersama dengan keluarga, maka peranan menyediakan penjagaan tentunya akan dipikul oleh keluarga. Kekangan kewangan, tanggungjawab sosial serta masalah lain juga menyebabkan peranan menjaga terus dilaksankan oleh keluarga.

Sehubungan dengan huraian di atas, makalah ini akan mengupas isu berkaitan dengan peranan gender dalam penjagaan tidak formal. Memandangkan penjagaan tidak formal mencakupi keperluan pesakit daripada pelbagai kategori penyakit, maka kertas ini tidaklah bertujuan membincangkan kesemuanya.Fokus adalah lebih kepada melihat dua aspek penting berkaitan dengan penjagaan.Pertama ialah tanggungjawab anakanak terhadap ibu bapa yang tua dan uzur atau yang mengidap penyakit kronik yang memerlukan penjagaan rapi.Kedua ialah perkaitan dengan perhubungan di antara pesakit dan penjaga. Kedua-dua aspek berkaitan dengan penjagaan itu akan dikupas dalam konteks ajaran Islam mengenai peranan anak-anak terhadap ibu bapa yang sudah tua, peranan ibu bapa terhadap anak-anak yang sakit atau kurang upaya dan hukum hakam berkaitan dengan hubungan antara penjaga dan pesakit khususnya jika mereka bukan mahram. Isu ini dilihat penting 
memandangkan adapihak yang melihat bahawa peranan menyediakan penjagaan itu lebih penting dengan mengabaikan pula isu yang berkaitan dengan hukum hakam perhubungan serta aurat antara penjaga dan pesakit.

Berdasarkan data daripada penyelidikan-penyelidikan yang pernah dilakukan tentang penjagaan tidak formal dalam keluarga dan komuniti (Fatimah et. al 2009, Fatimah 2006, Mohd Suhaimi 2010) serta data semasa daripada penyelidikan yang sedang dijalankan, makalah ini membincangkan isu yang dinyatakan di atas. Contoh-contoh daripada kes yang ditemui dibentangkan.Pada akhir makalah ini penulis mencadangkan bagaimana peranan penjagaan boleh diupayakan dari dalam keluarga dan komuniti serta bantuan pihak berkuasa agar peranan tersebut dapat dilakukan dengan berkesan danharmonis dengan tuntutan fizikal, sosial, psikologikal serta keperluan syariat Islam.

\section{Hasil dan Pembahasan \\ Makna Penjagaan Tidak Formal}

Penjagaan boleh berlaku secara formal atau tidak formal. Penjagaan formal lebih khusus kepada sebarang bentuk penjagaan yang disediakan di institusi dan dilaksanakan oleh individu tertentu yang telah diberi latihan khusus untuk melaksanakan peranan penjagaan. Di hospital, kebanyakan penjaga terdiri daripada para jururawat (perempuan dan lelaki), atau mereka yang bekerja di rumah-rumah orang tua. Kesemua penjaga dibayar gaji oleh institusi atau organisasi yang mengambil mereka bekerja. Mereka yang dijaga (atau keluarga mereka) pula perlu membayar sejumlah wang yang ditetapkan setiap bulan untuk mendapat perkhidmatan tersebut. Bayaran itu mungkin termasuk perkhidmatan yang disediakan seperti makanan, tempat tinggal dan keperluankeperluan asas yang lain yang disediakan oleh institusi penjagaan. Dalam konteks perhubungan sosial antara pesakit dengan penjaga pula, lazimnya penjaga formal tidak ada hubungan kekeluargaan atau persahabatan dengan individu yang dijaga (atau keluarga pesakit yang dijaga).

Penjagaan tidak formal pula adalah penjagaan yang disediakan oleh sektor bukan awam; seperti swasta, sukarela, sektor ketiga seperti ahli keluarga, jiran dan ahli masyarakat (Spicker 2008). Tradisinya, penjagaan tidak formal disediakan oleh individu yang tidak terlatih seperti ahli keluarga, jiran, dan sahabat-handai kepada pesakit. Cirinya yang paling unik adalah peranan yang dilakukan itu tidak melibatkan sebarang bentuk bayaran kewangan (Walker, Pratt \& Eddy 1995). Peranan itu dilakukan atas sebab-sebab pertalian darah dan hubungan perkahwinan, rasa kasih sayang dan tanggungjawab (Ungerson 1995). Tegasnya penjaga tidak formal tidak melibatkan individu profesional yang berkemahiran khusus dan melakukan tugas-tugas tertentu, dikenakan yuran, upah atau gaji dan berpandu kepada prosedur atau kaedah-kaedah penjagaan yang perlu dipatuhi.Penjagaan biasanya dilakukan dalam ruang persekitaran kediaman pesakit dan keluarga mereka. Dalam keadaan tertentu kerja menjaga itu dilakukan sepanjang hari sama ada bergilir-gilir antara ahli keluarga yang ada ataupun hanya oleh seorang sahaja. Jangka masa "bekerja" yang panjang ini boleh menyebabkan stres dan burnout kepada penjaga.

Ringkasnya, penjaga tidak formal dalam latar keluarga lazimnya terdiri daripada ibu bapa (jika mereka menjaga anak), anakanak lelaki dan perempuan, menantu (jika mereka menjaga ibu bapa), adik beradik, cucu (jika mereka menjaga datuk dan nenek), datuk dan nenek (jika mereka menjaga cucu yang kematian ibu bapa atau ibu bapa bercerai atau sakit), serta saudaramara lain seperti sepupu,adik beradik angkat, ibu atau bapa saudara sertajiran dan kawan-kawan. Dalam 
konteks semasa, pembantu rumah juga kerap menjalankan peranan sebagai penjaga dan menjaga mana-mana ahli keluarga di rumah majikan mereka.

\section{Sakit Kronik, Sakit Mental dan Ketidakupayaan}

Menurut National Center for Health Statistics Amerika Syarikat, penyakit kronik adalah penyakit yang kekal untuk jangkamasa yang lama, sekurang-kurannya tiga bulan atau lebih. Pertubuhan Kesihatan Sedunia (WHO) (2011) pula mendefinisikan penyakit kronik sebagai penyakit yang mengambil masa yang panjang dan lambat untuk sembuh.

Penyakit kronik lazimnya tidak dapat dicegah melalui viksin atau dirawat dengan ubatan, dan jarang sekali penyakit itu berhenti atau hilang dengan tiba-tiba (www.medicinet.com). Lazimnya pengidap penyakit kronik akan bertambah apabila usia meningkat. Kebanyakan penyakit kronik yang ditemui masa kini ialah atritis, penyakit kardiovaskular seperti serangan jantung dan strok, kanser (termasuk kanser payudara, kanser serviks, kanser kolon) diabetis, malah obesiti juga digolongkan sebagai penyakit kronik. Penyakit-penyakit seperti artritis dan yang berkaitan dengannya juga boleh menyebabkan ketidakupayaan.

Pesakit kronik rata-ratanya memerlukan penjagaan dan pemantauan rapi sepanjang masa untuk tempoh masa yang lama. Pesakit kronik memerlukan rawatan dan penjagaan yang lama dan konsisten. Oleh itu ia memberi kesan jangka panjang yang penting kepada penjaga dan keluarga terutama dalam hal-hal berkaitan ekonomi, fizikal dan emosi (Moonie et al. 2000). Keperluan kepada penjagaan yang berterusan sangat jelas bagi keluarga yang mempunyai ibu bapa yang tua dankurang upaya, atau anak kurang upaya, ahlinya yang sakit mental ataupun sakit kronik.Ini kerana apabila pesakit berkenaan didiscaj dari hospital, maka keluarga bertanggungjawab sepenuhnya menyediakan penjagaan, di samping mengikut prosedur yang telah ditetapkan oleh pihak hospital.Antaranya ialah jadual mengambil ubat, latihan fisioterapi, diet, menjaga kebersihan dan pertemuan dengan doktor untuk rawatan susulan.Ini bermakna perancangan aktiviti harian pesakit perlu ditetapkan dan dipatuhi.

Sakit mental pula menurut Akta Kesihatan Mental 2001 (Akta 615, p. 10) adalah kecelaruan mental yang disebabkan oleh gangguan atau halangan kepada perkembangan minda, kecelaruan psikiatri atau mana-mana kecelaruan atau ketidakupayaan minda untuk berfungsi dengan sepatutnya. Menurut Resner dan Hartog (1970 dalam Hashim, 1990) masyarakat Melayu mempunyai kriteria tertentu dalam melabelkan seseorang itu sebagai berpenyakit mental (gila) atau tidak. Antara kriteria yang digunakan ialah; (1) perlakuan yang ditunjukkan adalah lain daripada biasa seperti dari segi perawakan, perasaan dan tingkah laku;(2) perlakuanperlakuan yang luar biasa itu berterusan walaupun telah diusahakan pemulihan oleh bomoh; dan (3) ada unsur keganasan, sama ada benar atau khayalan. Seseorang boleh dikatakan sebagai berpenyakit mental jika memperlihatkan satu atau lebih daripada kriteria yang dinyatakan itu.

Jabatan Kebajikan Masyarakat Malaysia mengkategorikan sakit mental di bawah ketidakupayaan. Ini kerana pesakit mental lazimnya tidak berupaya berfungsi sama ada sebahagian atau sepenuhnya dalam hal berkaitan dirinya atau perhubungannya dalam masyarakat. is penyakit mental ialahOrganic Mental Disorder yang serius dan kronik, Skizofrenia, Paranoid, Mood Disorder (depression, bipolar) dan lainlain kecelaruan psikotik (psychotic disorder) seperti Schiqoaffective Disorder dan Persistent Delusional Disorders. Untuk memastikan seseorang itu dikategorikan sebagai mempunyai masalah mental dia mestilah telah 
menjalani rawatan psikatri sekurang-kurangnya dua tahun.

Ketidakupayaan pula boleh dibahagikan kepada beberapa kategori berdasarkan kepada ketidakfungsiaan anggota fizikal seseorang (termasuk juga ketidakfungsian mental sebagaimana yang disebut di atas). Jabatan Kebajikan Masyarakat Malaysia menyenaraikan beberapa kategori ketidakupayaan iaitu: (1) pendengaran apabila seseorang tidak dapat mendengar kedua-dua belah telinga tanpa bantuan alat pendengaran atau setelah diberi perlatan bantuan pendengan; (2) penglihatan - buta sebelah atau kedua-dua belah mata atau gangguan kepada penglihatan kekal; pertuturan - ketidakupayaan bertutur yang kekal menyebabkan gangguan berkomunikasi dengan sempurna dan tidak boleh difahami oleh orang yang berinteraksi dengannya; (4) fizikal - semua ketidakupayaan kekal anggota badan sidebabkan kehilangan atau ketiadaan atau ketidak upayaan mana-mana anggota badan yang yang menjejaskan fungsi untuk melakukan aktiviti seharian. Pesakit strok, Cerebral Palsy, kerdil adalah antara masalah yang menyebabkan ketidakupayaan fizikal; (5) masalah pembelajaran - berkaitan dengan kecerdasan otak yang tidak selaras dengan usia biologi. Termasuk dalam kategori ini ialah autisme (autistic spectrum disorder), Attention Deficit Hyperactivity Disorder (ADHD) dan masalah pembelajaran khusus seperti (dyslexia, dyscalculia dan dysgraphia); (6) bentuk ketidakupayaan lain yang tidak termasuk dalam kategori di atas dan juga sakit mental.

Sakit kronik, sakit mental dan ketidakupayaan itu memerlukan penjagaan rapi dan berpanjangan.Ini bermakna penjaga yang menjaga mereka mesti mempunyai kekuatan fizikal dan mental. Pada masa yang sama pesakit dan ahli keluarga mestilah mempunyai cukup sumber, khususnya kewangan untuk menanggung perbelanjaan yang berkaitan. Malah keperluan kepada penjagaan ganti (respite care) turut sama pentingnya agar kebajikan pesakit dan penjaga terjamin.

\section{Mengapa Penjagaan Tidak Formal Penting}

Penjagaan tidak formal menjadi isu yang semakin penting sejak kebelakangan ini.Hal ini mempunyai kaitan dengan beberapa faktor. Pertama ialah ketidakupayaan hospital untuk menerima atau meneruskan rawatan pesakit disebabkan kekangan daripada segi kemudahan yang terdapat di hospital seperti katil dan kemudahan-kemudahan lain. Kedua, bilangan mereka yang memerlukan jagaan yang berpanjangan kerana penyakit-penyakit yang dinyatakan lebih awal semakin bertambah.Ketiga, perubahan yang berlaku kepada institusi keluarga baik daripada segi pemisahan antara keluarga nuklear dan keluarga luas serta penglibatan wanita dalam pekerjaan di luar rumah menyebabkan fungsi keurga dalam menyediakan penjagaan sepenuhnya untuk ahli-hali keluarga yang memerlukan jagaan berpanjangan tidak dapat dipenuhi oleh keluarga.

Sungguhpun faktor-faktor yang dinyatakan di atas itu sangat memberi tekanan kepada kebanyakan keluarga.Bagi keluarga miskin, tuntutan untuk mencari nafkah dan memenuhi keperluan keluarga menyebabkan ahli keluarga yang berupaya perlu keluar bekerja atau terlibat dalam aktiviti produktif. Ini menyebabkan pesakit terpaksa ditinggalkan bersendirian untuk beberapa ketika semasa ahli keluarga yang lain keluar bekerja. Bagi keluarga yang berada, tidak semua ahli keluarga perlu keluar bekerja.Oleh itu ada yang boleh melaksanakan peranan sebagai penjaga. Malah dalam keluarga berkenaan mereka mungkin mampu mengambil pembantu atau mengupah orang lain sebagai penjaga.

\section{Isu Gender dalam Penjagaan Tidak Formal}


Data daripada kebanyakan kajian yang telah dilakukan berkenaan dengan penjagaan tidak formal mendapati bahawa sebahagian besar daripada penjaga adalah wanita.Kebanyakan mereka adalah ibu (yang menjaga anak yang sakit), anak perempuan (yang menjaga bapa atau ibu yang sakit kronik atau sakit tua), isteri (menjaga suami yang sakit kronik) dan menantu perempuan (yang menjaga ibu mertua). Selain itu terdapat juga pembantu rumah wanita yang merupakan pekerja warga asing (terutamanya warga Indonesia) yang diberi tugas menjaga ahli keluarga yang sakit (anak atau ibu kepada majikan mereka).

Sejak sekian lama peranan penjagaan itu dilakukan oleh wanita tanpa banyak soaljawab memandangkan peranan itu dilihat sebagai berharmoni dengan peranan lain yang dipertanggungjawab kepada mereka. sebagai contoh, sejak tradisi lagi wanita adalah penjaga kepada anak-anak kecil, menjaga ibu bapa yang tua atau adikberadik yang telah tua (terutamanya yang belum atau tidak pernah berkahwin). Sifat wanita yang lemah lembut, prihatin, mudah sempati dan teliti dalam kerja mereka menyebabkan tanggungjawab sebagai penjaga dengan mudahnya diberikan kepada mereka tanpa banyak soal jawab.

Tanggapan dan jangkaan berkaitan dengan peranan wanita sebagai penjaga itu tidak banyak berubah walaupun mereka telah keluar bekerja secara formal di luar daripada persekitaran atau lingkungan kerja.Apa yang berlaku ialah mereka tetap diharapkan untuk menjaga anak yang sakit, ibu bapa yang sakit, tua serta uzur. Di bahu mereka jugalah terletaknya peranan untuk menjaga suami yang sakit atau menjaga ibu mertua, lebih-lebih lagi jika ibu mertua mereka tidak mempunyai anak perempuan.justeru tidak hairanlah jika mereka juga dituntut untuk mengambil cuti atau berhenti kerja sama ada buat sementara atau selamanya agar dapat memikul peranan sebagai penjaga dengan lebih baik.
Cuti atau berhenti kerja tentulah tidak menjadi banyak masalah jika mereka dan keluarga mempunyai sumber pendapatan atau kewangan yang cukup bagi menampung perbelanjaan perubatan dan lain-lain keperluan pesakit.Malah keluarga sedemikian boleh juga mengambil pembantu untuk menjaga pesakit sepenuh masa atau menolong penjaga utama (wanita) dalam keluarga berkenaan.Sebaliknya bagi keluarga yang tidak mempunyai sumber pendapatan yang cukup, atau pekerja wanita yang tidak berkahwin atau ibu tunggal yang perlu menjaga ibu yang sakit, berhenti kerja bukanlah suatu yang mudah dilakukan.

Berkaitan dengan isu yang dihuraikan di atas itu maka meyerahkan peranan penjagaan kepada wanita semata-mata tentulah tidak sesuai malah tidak adil.Atau menyalahkan mereka kerana keluar bekerja dan tidak memberi tumpuan kepada penjagaan untuk ibu atau ahli keluarga yang sakit juga tentulah tidak sepatutnya dilakukan.Sehubungan itu peranan penjagaan perlulah dilihat sebagai tanggungjawab bersama bagi lelaki dan juga perempuan. Malah, sesetengah aktiviti penjagaan memerlukan kekuatan fizikal, sebagai contoh mengangkat pesakit sama ada untuk membersihkan diri dan tempat tidur pesakit atau membawa pesakit mendapat rawatan dan seumpamanya memerlukan kekuatan fizikal. Dalam sesetengah hal kekuatan emosi dan spiritual juga penting, ini kerana penjaga mungkin merasa penat, letih dan tidak bermaya lagi untuk mengendalikan tugas seharian. Oleh itu kerja penjagaan juga perlu diberi kepada ahli lain dalam keluarga termasuk lelaki. Selain itu jika pesakit adalah lelaki maka penjaga lelaki tentulah lebih sesuai kerana mereka lebih kuat dari segi fizikal.

\section{Senario Penjagaan Tidak Formal Semasa}

Maklumat berkaitan dengan isu gender dalam penjagaan tidak formal telah diperoleh daripada pengalaman penulis menjalankan 
beberapa kajian tentang keluarga (Fatimah 2006, 2015, Mohd. Suhaimi et. al2014) Behagian berikut adalah huraian mengenai senario penjagaan bagi dua kes-kes yang dipilih dengan tujuan memberi fokus tentang keprihatinan masyarakat, khsusnnya yang beragama Islam terhadap isu berkaitan dengan hubungan mahram dan aurat.

Kes 1.

Hakim berumur 25 tahun.Merupakan anak lelaki tunggal. Kakaknya berusia 36 tahun dan telah berkahwin dan tinggal berasingan. Ini bermakna Hakim tinggal bersama kedua ibu bapanya dan dua orang pembantu rumah.Nenek sebelah ibunya juga tinggal bersama tetapi kerana sudah tua, hampir 90 tahun dia tidak mampu bergerak sendiri dan membuat kerja-kerja di rumah. Kedua ibu bapa Hakim berusia awal 60-an dan mereka adalah usahawan. Bidang kerja tersebut memberi kelonggaran kepada mereka untuk berada bersama Hakim atau membawa Hakim bersiar2.

Hakim adalah remaja OKU (CP).Sejak lahir dia tidak pernah ke sekolah seperti kanakkanak lain tetapi kedua ibu bapanya telah membawa guru khas mengajarnya.Oleh kerana dia sukar bergerak dan kedua ibu bapanya juga perlu keluar kerana urusan kerja, maka sebahagian masa Hakim dijaga oleh pembantu rumah warga asing (Indonesia).Sejak kecil Hakim dipakaikan lampin pakai buang bagi memudahkannya membuang air dan senang dijaga oleh pembantu rumah.Makan minumnya juga dijaga oleh pembantu rumah dengan pengawasan ibu bapanya jika mereka berdua ada di rumah. Semasa kedua ibu bapanya menunaikan ibadat haji, Hakim dijaga oleh kakak dan emak saudaranya bersamasama dengan pembantu rumah.

Walaupun dia merupakan remaja OKU, tetapi Hakim sentiasa dibawa oleh ibunya (dan bapanya) bersiar-siar ke pasaraya, ke kedai buku dan restoran.Dia bolehmengendalikan kerusi rodanya sendiri tetapi lazimnya pembantu rumahlah akan meyorongnya ke sana sini.

Kes 2.

Puan Maiza, 40 tahun menjaga kedua ibu bapanya yang berusia 69 tahun dan 73 tahun. Bapnya mengidap penyakit jantung dan tekanan darah tinggi sementara ibunya mengidap kencing manis. Mereka berdua adalah pesara kerajaan tetapi telah lama tinggal bersama Puan Maiza. Walaupun mereka mempunyai beberapa orang anak yang lain tetapi kebanyakannya tidak "berminat" untuk menjaga kedua ibu bapa berkenaan. Lagipun Puan Maiza merasa lebih selesa apabila kedua ibu bapnya tinggal bersama disebabkan dia hanya mempunyai seorang anak perempuan sahaja, rumahnya besar dan mempunyai bilik serta ruang yang cukup untuk kedua ibu bapanya tinggal.Suaminya yang sentiasa tidak ada di rumah atas urusan kerja juga menyebabkan kehadiran kedua ibu bapanya dapat mengurangkan rasa sunti di rumah.Lagipun Puan Maiza mempunyi pembantu rumah yang boleh diharapkan untuk menjaga ibu bapanya semasa dia keluar bekerja.

Puan Maiza menanggung segala perbelanjaan makan minum kedua ibu bapanya. Walau bagaimanapun oleh pebelanjaan perubatan ditanggung olehibu bapanya sendiri kerana meraka ada wang pencen dan mendapat faedah daripada persaraan. Puan Maiza tidak melihat perbelanjaan perubatan untuk kedua ibu bapanya sebagai satu bebanan kewangan yang besar kerana dia mempunayi pendapat tetap yang agak besar juga dan anaknya pula hanya seorang masih di sekolah rendah.

Masalah lain dihadapi oleh Puan Maiza cumalah terpaksa membawa kedua ibu bapanya jika dia mempunyai urusan kerja di tempat lain. Ini kerana dia merasa bimbang untuk meninggalkan kedua ibu bapanya di 
rumah. Pilihan untuk membawa kedua ibu bapanya jika dia bekerja di tempat lain atau jika dia bercuti bersama suami dan anaknya itulah yang menyebabkan pereblanjaan keluarga meningkat sedikit pada masa-masa tertentu. Walau bagaimanapun dia percaya bahawa Allah telah menetukan rezeki untuknya.

Itu adalah dua contoh daripada beberapa kes mengenai penjagaan yang telah dikumpulkan daripada kajain yang telah dijalankan dan sedang dijalankan.Kes tersebut memperlihatkan dua isu penting yang menjadi fokus perbincangan dalam makalah ini iaitu berkaitan dengan penjaga perempuan serta peranan anak perempuan dalam penjagaan.

\section{Hukum-hakam Berkaitan dengan Penjagaan}

Sungguhpun menjaga orang sakit itu adalah satu tanggungjawab sosial yang penting, malah dituntut oleh agama tetapi isu yang berkaitan dengan siapa yang menjaga dan yang menerima jagaan tidak diberikan penekanan yang serius.Penjagaan tidak formal yang berlaku dalam keluarga pula selalu dilihat sebagai isu peribadi.Justeru, terpulanglah kepada keluarga masing-masing untuk menanganinya. Hakikatnya penjagaan merupakan satu yanggungjawab yang penting kerana ia boleh memberi maknayang penting mengenai keluarga dan komuniti yang terlibat. Selain itu peranan itu boleh meninggalkan implikasi yang penting bukan sahaja kepada kebajikan pesakit tetapi juga kepada perhubung sosial dan perpaduan sosial seluruhnya.

Jika diperincikan, isu berkaitan dengan penjagaan ini melibatkan beberapa aspek penting.Pertama ialah perhubungan fizikal di antara pesakit dan penjaga. Kedua ialah perhubungan dan tanggungjawab sosial serta ekonomi di antara kedua pihak tang terlibat (yakni pesakit dan penjaga).

\section{Perhubungan Fizikal}

Penjagaan merupakan aktiviti atau tugas yang banyak melibatkan perhubunganfizikal antara pesakit dengan penjaga. Dalam konteks agama Islam hal-hal yang berkaitan dengan batasan aurat telah dinyatakan dengan jelas.Terdapat keterangan yang jelas berhubung dengan aurat antara mahram dan bukan mahram.Sementara batas aurat yakni antara wanita muslimah di hadapan wanita bukan muslimah pula terdapat pandangan yang berbeza.Sebab perbezaan itu adalah kerana cara pemahaman yang berbeza terhadap ayat Al Quran yang terjemahannya seperti berikut:

"Dan jangan para wanita itu menampakkan perhiasan (aurat) mereka melainkan kepada suami-suami mereka... atau kepada para wanita mereka." (Al-Nur: 31).

Perkataan wanita (nisa') itu dimaksudkan (1) wanita (nisa') muslimah sahaja dan (2) dimaksudkan kepada semua wanita sama ada muslimah atau bukan. Pandangan yang diterima kebanyakan orang ialah harus wanita menampakkan auratnya di hadapat wanita bukan Islam melainkan jika dibimbangi berlakunya keburukan yang lain seperti bimbang wanita bukan Isalam itu akan menceritakan ciri-ciri tubuh badan wanita Muslim kepada lelaki anjabi, maka pada ketiaka itu wajib menutup aurat tidak kira di hadapan wanita kafir atau wanita muslimah yang rosak akhlaknya.

Antara bukti yang menunjukkan pandangan yang lebih benar ialah harus wanita Muslimah menampakkan auratnya di hadapan wanita bukan Islam ialah hadis 'Aisyah RA yang diriwayatkan oleh al-Bukhari dan Muslim yang menyebut seorang wanita Yahudi pernah menemui beliau ('Aisyah) di dalam rumahnya, dan tidak diriwayatkan beliau menutup aurat ketika itu. Al-Syeikh Abdul Aziz Abdullah bin Baz RH menyebut:

"(Wanita muslimah) Tidak wajib berhijab di hadapan wanita bukan Islam, mereka adalah 
sama seperti wanita lainnya berdasarkan pandangan yang lebih benar dari dua pandangan ulama yang ada."(Fatwa al-Mar'ah al-Muslimah 2/582).

Oleh yang demikian, aurat seorang wanita muslimah yang dibenarkan untuk dipeliharakan kepada wanita lain ialah aurat yang dibenarkan ketika dia bersama dengan mahramnya. Al-Syeikh Muhammad bin Soleh al-'Uthaimin berkata:

"Bagi seorang wanita muslimah itu dia boleh membuka aurat kepada mahramnya terdiri dari muka, kepada, lutut, dua tapak tangan dan hasta, dua betis dan lengan, manakala dia tutup aurat yang selain dari itu."Fatwa al-Mar'ah alMuslimah 1/417).

Justeru berkaitan dengan penjagaan pesakit, ahli keluarga terdekat sepatutnya bertanggungjawab untuk menjaga pesakit, terutamanya jika mereka berada di rumah ${ }^{1}$.Memandangkan penjagaan banyak melibatkan sentuhan fizikal, maka perhatian yang sewajarnya mengenai hal ini perlu diambil.Dalam kes pertama berkaitan dengan remaja OKU yang dijaga oleh pembantu rumah itu sangat relevan untuk diberikan perhatian oleh keluarga yang berkaitan agar isu yang melibatkan hukum hakam dijaga.

\section{Tanggungjawab sosial dan ekonomi}

Menjaga ahli keluarga yang sakit dan kurang upaya merupakan tanggungjawab penting keluarga.Kebanyakan keluarga mendaftarkan anak-anak atau ahli keluarga mereka yang kurang upaya dengan Jabatan Kebajikan Masyarakat (JKM) dan layak menerima bantuan bulanan OKU.Walau bagaimanapun perana menjaga masih dipikul oleh ahli keluarga terdekat yakni ibu bapa, anak-anak yang dewasa, adik beradik yang lebih tua.

${ }^{1}$ Isu berkaitan dengan penjagaan di institusi di mana jururawat perempuan atau penjaga perempuan merawat dan menjaga pesakit lelaki yang bukan mahram tidak disentuh dalam kertas ini.
Dalam konteks perhubungan sosial, pesakit lazimnya dilihat sebagai mereka yang tidak berkuasa (daripada segi fizikal), justeru tertaaluk kepada arahan daripada orang lain yang menjaganya. Penjaga dilihat sebagai orang yang lebih berkuasa.Di sini pola perhubungan adalah tidak seimbang atau berat sebelah di mana pesakit perlu mengikut arahan penjaga.Penjaga pula boleh mengenakankuasa yang dia ada untuk mengawal pesakit.Kawalan itu boleh berupa kawalan daripada segi pergerakan, makan minum, akses kepada rawatan, tempat tinggal yang bersih kemas dan selesa serta pelbagai lagi.

Apa yang kerap dipaparkan dalam berita atau laporan akhbar ialah pesakit dinafikan kemudahan sebagaimana yang dinyatakan itu. Kawalan ini tentunya lebih teruk dihadapi oleh pesakit mental atau pesakit warga tua. Banyak kes daripada kajian yang telah dilakukan (Fatimah et. al 2009) mendapati bahawa pesakit mental contohnya dikurung di rumah aatau pondok berasingan atau di tempatkan di atas loteng bagi mengelakkan mereka daripada mengacau orang lain atau melakukan sesuatu yang boleh menimbulkan masalah kepada keluarga atau penjaga. Ada juga pesakit yang dinafikan makan minum, tidak mandikan atau dibersihkan pakaian serta tempat tidurnya untuk beberapa lama.Sedangkan perbuatan sedemikian adalah bertentangan dengan ajaran agam (Islam) lebih-lebih lagi jika perbuatan itu dilakukan ke atas ibu bapa yang telah tua.

Daripada sisi yang lain pula ialah tanggungjawab sebagai penjaga banyak dibebankan kepada perempauan, terutama anak perempuan, isteri, ibu, malah menantu perempuan. Tindakan itu dijustifikasikan dengan peranan wanita yang lemah lembut, pengasih dan penyayang serta prihatin itu sangat cocok dengan peranan sebagai penjaga.Walau bagaimanapun apa yang berlaku sebenarnya ialah mereka bukan sahaja menjadi penjaga, tetapi memperuntukkan sejumlah 
wang setiap bulan sebagai belanjan untuk rawatan perubatan, makanan dan keperluan lain.Malah mereka juga terpaksa memperuntukkan masa untuk membawa ibu bapa berjumpa doktor. Jika terpaksa bekerja di tempat yang jauh, ibu bapa terpaksa dibawa bersama. Adik beradik yang lain (termasuk adik beradik lelaki) tidak menunjukkan kesediaan untuk membantu. Justeru beban penjagaan ditanggung sepenuhnya oleh penjaga (yakni anak perempuan).

\section{Apa yang Harus Dilakukan}

Makalah ini telah membentangkan latar belakang berkaitan dengan keperluan penjagaan tidak formal.Senario berkaitan dengan keperluan kepada penjagaan tidak formal juga telah dihuraikan berdasarkan kepda beberapa contoh kes yang khusus yang diambil daripada data kajian yang sedang dijalankan.Sebagaimana yang dinyatakan dalam bahagian awal makalah ini iaitu kebanyakan penjaga yang menyediakan penjagaan tidak formal adalah wanita.Justeru, perkara penting perlu diberikan perhatian ialah berkaitan dengan keperluan mendidik individu, keluarga dan komuniti agar prihatin dalam hal-hal berkaitan dengan hak batasan aurat dan hubungan di antara penjaga dan pesakit yang dijaga. Antara perkara penting ialah:

1. Pengupayaan penjaga lelaki dalam keluarga dan komuniti. Hal ini sangat penting kerana tidak semua pesakit adalah perempuan. Ahli keluarga dan komuniti perlu diberi pendedahan bukan sahaja daripada segi bagaimana menjadi penjaga yang efektif tetapi juga menyedarkan mereka tentang tanggungjawab atau tuntuan agama berhubung dengan peranan lelaki dalam menyediakan penjagaan untuk kaum lelaki.

2. Penjaga gantian. Peranan penjaga gantian (respite care) sangat penting terutama dalam mengurangkan tekanan yang dihadapi oleh penjaga utama. Ini kerana jika penjaga utama berhadapan dengan stress, sama ada kerana kehendak pesakit yang berbagai ragam dan gangguan kepada pola tidurnya boleh menjejaskan kesihatan penjaga dan seterusnya kualiti penjagaan yang dapat disediakan.

Berkait dengan yang 1, dan 2, latihan untuk menjadi penjaga perlu diberikan kepada setiap ahli keluarga dan komuniti sama ada melalui aktiviti sukarela yang berasaskan kejiranan, masjid dll.Penerangan mengenai perhubungan penjagaan mengikut sunnah dan ajaran Islam.

3. Kerjasama pelbagai agensi. Memandangkan kebanyakan pkeluarga tidak dapat menyediakan penjagaan untuk ahli keluarganya yang sakit atau kurang upaya disebabkan oleh pelbagai kekangan, maka kerjasama pelbagai agensi sangat penting dalam menyediakan penjagaan tidak formal serta membantu keluarga yang memerlukan penjagaan tidak formal.

4. Ganjaran dalam bentuk kewangan kepada penjagan. Kerja menjaga bukan sahaja melibatkan tenaga dan masa tetapi juga wang ringgit untuk merawat dan memberi barang-barang keperluan pesakit. Jika penjaga terpaksa berhenti kerja atau bertukar kepada kerja separuh masa atau kerja sambilan sudah tentu pendapatam mereka akan berkurangan. Pesakit pula rata-ratanya tidak bekerja, terpaksa berhenti kerja atau pun bernagtung kepada wang pencen. Justeru, sudah sampailah masanya agar para penjaga diberi ganjaran yang sepatutnya kepada kerja penjagaan yang mereka lakukan. Justeru isu penting berkaitan dengan penjagaan 
tidak formal ini ialah menyediakan institusi khas yang bertindak sebagai badan yang menjaga kebajikan para penjaga. Institusi ini diharap berupaya menjadi kumpulan pendesak bagi menuntut elaun khas sebagai penjaga tidak formal sebagaimana yang dilakukan di Britain dan Amerika Syarikat serta beberapa negara lain.

\section{Kesimpulan}

Isu penjagaan adalah isu sepanjang hayat. Walaubagaimanapun ia menjadi semakin penting sejak kebelakangan ini disebabkan pelbagai penyakit kronik dan ketidakupayaan ahli keluarga untuk menyediakan perkhidmatan itu sepenuhnya disebabkan pelbagai kekangan. Pelbagai cara telah diambil oleh keluarga yang berkaitan untuk menyediakan penjagaan yang terbaik kepada ahli keluarga mereka sama ada dengan menempatkan di institusi berbayar ataupun meneruskan penjagaan di rumah dalam persekitaran dan latar kehidupan keluarga.

Tidak kira di mana mereka dijaga isu berkaitan dengan perhubungan antara penjaga dan pesakit khususnya dalam hal-hal berkaitan dengan aurat (lebih-lebih lagi dalam konteks orang Melayu beragama Islam) dan tanggungjawab mahram kurang diberikan penekanan.Sehubungan itu berdasarkan kepada senario yang ditemui dalam kes-kes yang dibentangkan dan data daripada beberapa kajian yang telah dilakukan, makalah ini berpendirian bahawa sudah sampailah masanya ahli keluarga lebih prihatin dengan hal ini.Malah organisasi yang menyediakan perkhidmatan penjagaan juga perlu menitik beratkan isu ini.Selain itu pendidikan keagamaan berkaitan dengan hukum-hakam tentang tanggungjawab dan aurat ini perlu diberi penekanan agar kesemua pihak tidaklah terpalit dengan dosa (walaupun dilihat kecil sahaja).

\section{Senarai Rujukan}

Akta Kesihatan Mental 2001

Al Quran

Fatimah Abdullah. 2006, "Fungsi keluarga dalam penjagaan". Kertas kerja dalam Seminar Psikologi dan Masyarakat: Pendekatan Psikososial dalam Pengupayaan Pembangunan Komuniti.Pusat Pengajian Psikologi dan Pembangunan Manusia, Universiti Kebangsaan Malaysia, Bangi.

Fatimah Abdullah, Mohd. Suhaimi Mohamad, Nor Jana Saim dan Nur Saadah Mohamad Aun, 2009. Fungsi Keluarga dalam Penjagaan: Kes Penjagaan Pesakit Mental dalam Keluarga dan Komuniti. Laporan penyelidikan UKMSG-05-FRGS0012-2006.Tidak diterbitkan.

Fatimah Abdullah. 2009. "Isu dan cabaran penjagaan tidak formal" dlm. The Malaysian Journal of Social Administration Bil.9, hlm.73-86.

Fatimah Abdullah. 2015. Urbanisasi dan Perubahan Keluarga. Data Penyelidikan (tidak diterbitkan)

Fatwa al-Mar'ah al-Muslimah 1/417

Fatwa al-Mar'ah al-Muslimah 2/582

Hashim Awang A. R., 1990. Pengantar Antropologi Kesihatan. Kuala Lumpur: Dewan Bahasa dan Pustaka.

Jabatan Perangkaan Malaysia 2016.Jadual Hayat Ringkas, Malaysia, 2013-2016 https://www.dosm.gov.my/v1/index.p $\mathrm{hp} ? \mathrm{r}=$ column/pdfPrev\&id $=\mathrm{VStSWHZ}$ GRIZIZIZvOE9VVWcybGpGQT09

Mohd. Suhaimi Mohamad, 2010. 'Families' experiences of caregiving to relatives with a diagnosis of Schirophrenia in Malaysia". Tesis Ijazah Doktor Falsafah. Center for Research in Health and Social Care, School for Social Policy Studies, University of Bristol, England.

Mohd Suhaimi Mohamad, Rahmah Mohd Amin, Nasrudin Subhi, Fauziah Ibrahim, Khadijah Alavi, Norulhuda Sarnon \& Chong Sheau Tsuey. 2014. Developing family caregiving inventory for 
sandwich generation - membentuk inventori penjagaan keluarga generasi "sandwich". In Social Science: Directory of research projects: fundamental research grant scheme (FRGS). Fasa 2011, Kementerian Pengajian Tinggi Malaysia.

Moonie, N. 2000Advanced: Health and Social Care. Oxford: Heinemann Educational Publishers.

Spicker, P. 2008. The Provision of Welfare Social Policy: Themes and Approaches. Bristol: Policy Press.

Ungerson, C. 1995. "Gender, cash and informal care: European Perspectives and dilemmas" dlm. Journal of Social Policy 25:1, hlm.31-53, 1995.

Walker, A. J., Pratt, C. C., dan Eddy, L., 1996."Informal Caregiving to Ageing Family Members: A critical review" dlm.Family Relations 44, hlm. 402-11.

WHO 2011 national center for health statisticsWorld Health Organization dan The World Bank (2011).'World Report on Disability".

http://www.who.int/disabilities/world repo rt/2011/report.pdf

www.medicinet.com 